\title{
'Public Administration in an Age of Austerity': Positive Lessons From Policy Studies
}

\begin{abstract}
A key aim of this special issue is to demonstrate the enduring insights of public policy studies during periods of political crisis and significant policy change. This article establishes our ability to accumulate knowledge in a field often characterised by changing empirical circumstances and changing theories. Theoretical and conceptual advance may be necessary to capture new developments, but must also be balanced with the need to build on what we already know. Periods of crisis may encourage us to upset that balance. They often encourage the idea that political change and behaviour is unprecedented; that new policymaking circumstances are unique, or at least so different from the past that it is difficult to learn lessons from history and current theories. In short, the usual rules do not apply and, by extension, we need new theories that account for new practices. However, new tools need to be judged against our existing collection.
\end{abstract}

\section{Introduction}

A key aim of this special issue is to demonstrate the enduring insights of public policy studies during periods of political crisis and significant policy change - such as the UK's current 'age of austerity' and the current UK Government's significant response. Recent UK experience shows us that the idea of a majoritarian political system, able to produce rapid and radical policy change, is difficult to shake. The production, by any UK government, of a series of high profile and controversial decisions reinforces in our minds the image of a 'Westminster Model' or 'British Political Tradition' and all that goes with it: top-down, government knows best policymaking in which Prime Ministers are presidential and ministers make tough (and often unpopular) choices unencumbered by the need to compromise and negotiate with actors outside government. Consequently, consultation with 'pressure participants' (Jordan et al, 2004) such as implementing organisations and interest groups is minimised (Cairney, 2011a; see also Lijphart, 1999 and Rhodes, 2011: 23 on the 'Westminster narrative'). This narrative was invoked by Finer (1975) to criticise the UK policy style; identifying an adversarial style of politics combined with an electoral system which exaggerates voting majorities to cause regular changes of government and wholesale shifts in public policy. This policymaking image has also been used extensively to interpret both the Thatcher and Blair governments. Indeed, it is still a key narrative in UK politics despite the formation, in 2010, of a coalition government. ${ }^{i}$ The new Prime Minister David Cameron has made some use of this image and tradition, hailing his government's first Queen's Speech as a 'radical programme for a radical government' (BBC News, 2010). 
The programme was also accompanied by a commitment to make radical reforms to reduce spending - in areas such as welfare, higher education and healthcare - and therefore reduce the UK's levels of debt (and protect its credit rating during a period of high borrowing).

Without the benefit of hindsight, this production of an unusually high number of controversial decisions in such a short period of time would seem to reinforce and perhaps even extend the UK's majoritarian image. We may be tempted to conclude that the current economic crisis is unprecedented and that the requirement for so many 'tough choices' will have a radical effect on public policy. Certainly, the appearance of economic and political turmoil tends to produce unusual levels of media and public attention to government decisions, with many commentators very quick to make judgements about the long term consequences of short term commitments. Yet, with the benefit of hindsight, we know that there is a large gap between the image of UK policymaking and actual political behaviour and policy outcomes (indeed, the 'Westminster model' is used widely to describe what does not happen in British politics). The 'muscular' image reflects and reinforces a skewed and faulty understanding of the 'British policy style' (policy style is often defined simply as the way that governments make and implement policy - Richardson, 1982; Jordan, 2011; Cairney, 2011b). While examples of top-down policymaking are important and deserving of considerable analysis, we should also consider the analytical consequences of focusing too much on limited examples of centralisation. If we confirm that core executives are important by focusing on what they are doing, and confirming their importance in a small number of high profile areas, we neglect to consider the opportunity costs of their action and the policy issues that they cannot influence (Cairney, 2011a: 209).

Studies of public policy have long provided the material to moderate such extreme pictures of policymaking. They draw our attention to the factors that help produce continuity by reducing the ability of policymakers to change policy radically without reference to existing political settlements. The lesson from past studies is that political systems tend to enjoy a considerable level of policy continuity. Radical change in one issue tends to be atypical, with moderate change apparent in most others. Consequently, recent events in the UK may reinforce, not undermine, the value of public policy analysis. They should not necessarily force us to reconsider the tenets of the discipline fundamentally. Rather, they may prompt us to remember just how useful those tenets are.

In this context, the aim of the article is to establish the academic equivalent of an 'institutional memory'; to establish how a longstanding body of policy science identifies both continuity and change in policymaking and policy even during periods of crisis. 
This is not a straightforward task because there are two main purposes of the policy sciences. The first is to accumulate knowledge and generalisable concepts, based on the long and short term history of public policy, to inform current interpretations of policymaking. The second is to update and refine those concepts to reflect changing political circumstances. The relationship between these two practices may often be tense; a constant challenge to the accumulation of enduring concepts and knowledge is that the public policy literature often changes too quickly to reflect new fashions (linked occasionally to the importation of concepts from the physical sciences). This practice may compound the tendency towards providing 'new' concepts which produce a lack of clarity regarding their link to old concepts and the extent to which we are describing new phenomena as well as new ideas (Keating, 2009: 301). Our aim in this context is to identify points of continuity and change in the study of public policy; to strike a balance between the need to reconceptualise the world and to use existing concepts to explain it. In other words, our study of continuity and change in policymaking goes hand in hand with our consideration of continuity and change in the study of policymaking.

To this end, the article is divided into three sections. First, it considers a long term move in the literature, from the early post-war focus on the 'policy sciences' and the relatively small world of rational decision making, towards modern theories that seek to explain more open, complex and dynamic policymaking arrangements. This move demonstrates the necessity for conceptual advances to reflect new understandings of the world and new policymaking circumstances, but also highlights that such advances took decades to develop and refine. They were not produced at short notice following a period of unprecedented crisis. Rather, they developed as a response to problems and new ideas raised within the existing literature. Second, it considers the extent to which modern theories and concepts arise following (a) changing policymaking practices and conditions or (b) analytical fashions. It compares the more established studies of governance, punctuated equilibrium theory and the advocacy coalition framework with the relatively recent emergence of complexity theory. In each case, we should consider the extent to which such concepts are new, to reflect new circumstances, or build on existing theories and approaches. The article suggests that new theories are often most useful when used to reconsider longstanding conceptual problems - such as how to describe the limits to policymaker power, and the complexity of the economic and political systems in which they operate, without concluding that have almost no choice or control over the fate of their policy choices (the structure and agency problem). Third, it proposes a set of principles which should underpin the study of policymaking during periods of crisis and stability. These principles are based on the need to accept not only new terms to reflect new circumstances but also a degree of continuity in policymaking and the study of policymaking.

\section{The Policy Sciences and Comprehensive Rationality}


The way that we study public policy has changed significantly since an initial post-war focus on the 'policy sciences'. This shift of approach is easy to oversimplify and exaggerate, but we can identify the same basic narrative in a range of studies: the world has changed and so too has the way in which we try to understand it. In particular, modern accounts do not support the idea of top-down decision making pursued by a sole central actor. Rather, they situate such action within a more complex policy process.

A key narrative of policy studies in the early 1950s is that the policy sciences developed to reflect a belief that apparently new scientific methods should be applied to policy analysis (Lerner and Lasswell, 1951; Parsons, 1995: 16-28; Radin, 2000). It was part of the optimism of the early post-war period in which science and scientists could be called upon to solve society's problems. The assumption was that policy analysis could be used to better understand and make decisions and there was, perhaps initially, a less significant sense of uncertainty about our ability to understand and solve problems and the ability of policymakers to control the policymaking world in which they operated (Cairney, 2012: 5). The overall direction of policy was driven by a small number of policymakers at the centre who relied on an elite group of policy analysts to produce 'objective' ways to gather facts, analyse and solve problems (Radin, 2000: 15; 34; Howard, 2005: 4).

Two related approaches or ideas developed in this context. First, the idea of comprehensive rationality is that elected policymakers translate their values into policy in a straightforward manner. They have a clear, coherent and rank-ordered set of policy preferences which organisations carry out in a 'logical, reasoned and neutral way' (John, 1998: 33). There are clear-cut and ordered stages to the process (aims are identified, the means to achieve those aims are produced and one is selected) and analysis of the policymaking context is comprehensive. Second, the policy cycles approach developed as a way to organise policymaking. The suggestion is that policymakers should divide the process into a series of stages to ensure policy success: identify policymaker aims, identify policies to achieve those aims, select a policy measure, ensure that the selection is legitimised by the population or its legislature, identify the necessary resources, implement and then evaluate the policy (Cairney, 2012: 6).

It is important not to overstate academic and policymaker adherence to what we might now call a naive approach to policy analysis, particularly since early discussions of comprehensive rationality produced Simon's (1947; 1976: xxviii) concept of 'bounded rationality' and Lindblom's (1959; 1979) identification of incrementalism, both of which still underpin modern policy analysis (below). Yet, it is still worth noting that we have largely moved on from the idea that comprehensive rationality and stage-based 
decision-making are ideals to aspire to, towards the understanding that they are idealtypes used to describe how policymaking really works (by comparing the ideal-type with reality). Comprehensive rationality is used to explain why policymaking cannot be comprehensively rational, while the cycles approach is generally identified to show us why it is difficult or impossible to separate policymaking into stages (although compare pages 6 and 41 in Cairney, 2012). In this sense it is tempting to argue that there has been a disciplinary punctuation (akin to Baumgartner and Jones' 2009 policy punctuations) or a paradigm shift (akin to Hall's 1993 analysis, drawing on Kuhn 1962) since the post-war period. Indeed, one of the most influential modern treatments of policy theory appears to be built on a wholesale rejection of the policy cycles approach (see Sabatier, 2007: 7). Yet, this is a difficult call to make because there is still some continuity in the discipline. Unlike in Kuhn's (1962) analysis of paradigm shifts in the natural sciences, it is difficult to identify a single coherent approach followed by a complete break and a wholesale rejection of insights from the past.

What we can say with more certainty is that our object of study has changed somewhat and new approaches have developed to conceptualise that new world (Cairney, 2012: 42). For example, there is a diminished sense of optimism regarding the government's ability to solve problems through objective scientific analysis; the status of policy analysis has diminished (John, 1998: 32-3) and policy scientists now have to compete with many other actors for policymaker attention. We have also witnessed what Heclo (1978: 94) describes as an end to the 'clubby days' of US politics and Jordan (1981: 96100) links, in other countries such as the UK, to a shift from corporatism towards a more fragmented system with many more policy participants. A rise in governmental responsibilities not only mobilised more groups but also stretched the government's resources, producing its increased reliance on outside advice. This rise in activity from multiple sources, combined with the reduced exclusivity of policy analysis, often caused issues which were once 'quietly managed by a small group of insiders' to become 'controversial and politicized' (Heclo, 1978: 105). Further, our focus has shifted from the idea of one policymaking centre to multiple centres or sources of authority; power has dispersed from a single central actor towards many organisations and sources of authority and influence. Overall, the policy environment now seems more complex and potentially unstable, populated by more fragmented governments and many participants with different values, perceptions and preferences (Sabatier, 2007: 3-4). In short, it is increasingly difficult to identify policy driven solely from the centre or from the topdown.

\section{Theories of Subsystems, Governance and Complexity}

Instead, modern theories seek to capture and explain a more complex, fluid and multilevel policy process. The development of now well-established literatures (on 
governance, punctuated equilibrium theory and the advocacy coalition framework) and the relatively new literature on complexity theory show us two ways in which theories can develop to explain such major changes in our object of study. The former built on concepts and empirical work found in the existing literature, while the latter derived in part from the natural sciences and involves the adoption of what often appears to be a new language to explain policymaking.

Governance is a term used widely, to discuss not only changes in domestic policymaking arrangements but also global policy processes and even corporate responsibility (Rhodes, 1997; Kjaer, 2004). For our purposes, it describes two related factors: the sharing of power between government actors formally responsible for making decisions and those with which they consult and negotiate; and, the limited extent to which governments can enforce the implementation of their policy choices (Cairney, 2012: 157). In turn, 'multi-level governance' describes the dispersion of power from national central governments to other levels of government and nongovernmental actors. It stresses the blurry boundaries between formal sources of authority and informal sources of influence when decisions are made in a rather messy policymaking arena.

The multi-level governance literature developed in part as a consequence of changing political circumstances. For example, UK governance studies seek to capture the intended and unintended consequences of state reforms which included: privatisation (including the sale of public assets, extension of public-private partnerships in major capital projects and the charging for public services); the introduction of quasi-markets and injection of competition within public services; the reform and 'agencification' of the civil service; and the increased use of quasi- and non-governmental bodies to deliver public services (Rhodes, 1994). They combine with a focus on the increasingly vital role for the EU, and devolved or regional sources of policy, to explore a shift from old notions about UK central government control towards power diffusion and negotiation across multiple levels (see Cairney, 2012: 158-62 for reference to the 'hollowing out' debate and comparisons between MLG and the 'Westminster model'). In other words, this is a new area of study which may require new concepts.

Yet, the governance literature also drew heavily on existing work, including the idea of interdependence outlined in studies of policy communities and networks, and the idea of an 'implementation gap', or the gap between the expectations of policymakers and the final outcome. The policy communities literature often describes the regularity and importance of group-government relationships in functional terms: the size and scope of the state is so large that it is in danger of becoming unmanageable. Consequently, its component parts are broken down into policy sectors and sub-sectors, with power spread across government and shared with interest groups. Ministers and senior civil 
servants devolve the bulk of decision-making to less senior officials who consult with groups and exchange access for resources such as expertise. This exchange is based on the 'logic of consultation' with the most affected interests; it encourages group 'ownership' of policy and maximises governmental knowledge of possible problems (Richardson and Jordan, 1979; Jordan and Maloney, 1997). 'Policy community' (Richardson and Jordan, 1979; Jordan, 1990) describes this relationship between civil servants and certain interest groups.

In some accounts, this stability hinges on socialisation. ${ }^{\text {ii }}$ Membership of the community is often based in part on the willingness of its members to follow and enforce the "rules of the game'. When civil servants and groups form relationships, they recognise the potential benefits - such as stability and policy continuity - of attempting to insulate their decisions from the wider political process. Inclusion within the community depends on the gaining of personal trust; the learning process involves immersion within a 'common culture' in which there is strong agreement on the nature of, and solutions to, policy problems (Wilks and Wright, 1987: 302-3; McPherson and Raab, 1988: 55). In other cases, we may simply find that policy communities appear to be insulated because few participants pay attention to them. In particular, 'boundedly rational' policymakers can only pay attention to a small proportion of issues for which they are responsible (Simon, 1976; Baumgartner and Jones, 2009). Consequently, relationships between civil servants and groups often continue for long periods with minimal ministerial involvement, and policymakers at the 'top' do not have the ability to impose their will systematically across government.

Nor do ministers have the resources to pay attention to, and oversee the successful implementation of, their policy choices. Contemporary discussions of governance link this problem to the unintended consequences of previous decisions (privatisation, market-based reforms, agencification and new forms of service delivery) which have exacerbated the fragmented nature of the UK state and undermined the ability of core executives to drive policy from the centre: 'centralisation will be confounded by fragmentation and interdependence that, in turn, will prompt further bouts of centralisation' (Bevir and Rhodes, 2003: 6). However, they also draw on our longer term understanding of implementation, such as the 'top-down' approach that identifies a series of factors to explain the implementation gap from the perspective of policymakers (including a lack of clarity of aims, insufficient resources, low interest group support and low compliance among implementing organisations) and the 'bottom-up' approach that considers policymaking processes from the perspective of 'street level bureaucrats' (Lipsky, 1980; Hupe and Hill, 2007) or actors within 'implementation structures' (Hjern, 1981; Hjern and Porter, 1982; see Cairney, 2009a: 357; 2012: 34-8). 
We can present similar narratives of continuity and change in the US-derived theories which now represent a key part of UK policy studies: they describe and explain a complex, fluid and multi-level policy process using a combination of old and new concepts. Punctuated equilibrium theory ${ }^{\text {iii }}$ originally sought to explain shifts from stable and insulated policy community relationships towards the more open and competitive arrangements we associate with issue networks (Heclo, 1978). Baumgartner and Jones' (1993) case studies drew on the agenda setting literature to identify policy punctuations when 'policy monopolies' endured for long periods before breaking down. For example, stable and insulated relationships between government regulators, Congress and nuclear power companies developed (and endured for decades) when nuclear power was framed successfully as the solution to several energy problems (including rising costs and increased dependence on imported energy) and the details of implementation were devolved to experts - an outcome that effectively excluded most other actors. However, those relationships broke down following a surge of public, media and congressional attention to nuclear safety (prompted largely by the Three Mile Island crisis) that prompted policymakers to reconsider their attitude to nuclear power, consult with far more organisations and, subsequently, regulate the industry more heavily (1993: 59-82).

Their subsequent 'general punctuation hypothesis' extends these insights to policymaking as a whole, drawing on our understanding of bounded rationality to identify the 'selective attention' of policymakers when they process information; their disproportionate attention to a small number of issues at the expense of most others (Jones and Baumgartner, 2005: 8; 18). The hypothesis has been confirmed in an increasing number of comparative studies of government budgets (and legislative change), which highlight a huge number of small changes in each policy category ('hyperincrementalism'), combined with a small number of huge changes (True et al., 2007: 166; Jones and Baumgartner, 2005: 8; 18; Baumgartner et al, 2009; Jones et al, 2009). The extent to which this approach departs profoundly from Lindblom's (1959; 1979) discussion of incrementalism is still an open question (see for example Baumgartner and Jones, 2009: 251).

The key point to note for our purposes is that, while this is a new and innovative theory, its intellectual history in the group-government and agenda setting literatures is still clear. For example, Baumgartner's work on agenda setting was influenced to some extent by his mentor, Kingdon $(1984 ; 1995)$, who in turn drew on the 'garbage can' model of policymaking (in which the identification of aims, production of solutions, and selection of choices represent independent streams - Cohen et al, 1972) and the metaphor of evolution to identify the importance of 'multiple streams': lurches of attention (in the 'problem' stream') combine with sources of stability (the need for policy solutions to evolve gradually in the 'policy' stream) and choice (the need for 
policymakers to be receptive to an idea and motivated to adopt it in the 'politics' stream) during a brief 'window of opportunity' for policy change.

The advocacy coalition framework is set up more as a departure from previous approaches. Its main source of criticism is the policy cycles approach (or 'stages heuristic') which Sabatier (2007: 7; Sabatier and Jenkins-Smith, 1993) describes as outdated, inaccurate, unscientific and misleading (see also Sabatier, 1991: 149 on Kingdon, Hofferbert and Ostrom). It also departs from the idea of small, closed policy communities or monopolies by describing policy subsystems inhabited by advocacy coalitions with wide memberships (including journalists, academics and actors from multiple levels and types of government). However, we can still see several points of acknowledged continuity. Most notably, the ACF derives in part from its attempts to: get beyond the 'top-down versus bottom-up' debate on policy implementation (Sabatier, 1986); extend Majone's (1980) work on the importance of beliefs and theories which underpin policy instruments; and, progress from the 'Dye-Sharansky-Hofferbert' approach to systems theory, which seeks to explain policy outcomes with reference to socio-economic conditions (see Blomquist, 2007: 270-1).

\section{Contemporary developments - the contribution of complexity theory}

In a broad sense, complexity theory seeks to explain behaviour in terms of the 'whole' rather than the 'sum of its parts' and identifies: 'non-linear dynamics' when some forms of action are amplified and others dampened (by positive and negative feedback provided by complex systems); 'sensitivity to initial conditions' or the cumulative effect of early events; 'emergence' (when systems appear to behave independently or defy central control); and, 'strange attractors' or regularities of behaviour despite the unpredictability of complex systems (Blackman, 2001; Bovaird, 2008: 320; Cairney, 2012: 124-5; Geyer and Rihani, 2010; Geyer, 2012; Kernick, 2006; Little, 2012; Mitchell, 2009: x; Mitleton-Kelly, 2003: 25-6; Teisman and Klijn, 2008). In political science, its growing popularity may relate to the impression it gives about the unpredictability of large political systems and, perhaps, the apparent inability of policymakers to exert control or for their policies to have the desired effect (there are also notable attempts to translate complexity theory into advice for policymakers Room, 2011; Hallsworth et al, 2011).

For our purposes, the importance of complexity theory is that the links to existing policy theory are relatively unclear. It is tempting to view complexity theory as not only a break from the literature, as an import from the physical sciences, ${ }^{\text {iv }}$ but also the polar opposite of the 'Westminster narrative' (if the latter stresses the primacy of a small number of central government actors and the former highlights their inability to control the policymaking world for which they are ostensibly responsible). Yet, as we begin to 
examine its insights further, we find that complexity theory becomes more meaningful when grounded in concepts with which we are already familiar (and indeed, some of its theoretical development has come from social science). For example, sensitivity to initial conditions is a feature of the literature on path dependence and historical institutionalism (Pierson, 2000), non-linear dynamics are features of Jones and Baumgartner's (2005: 7) work on information processing, and 'emergence' links well to the literature on bottom-up policymaking (Cairney, 2012: 126-8). Further, the policy advice that generally derives from complexity theory (learn from experience, use trial and error, adapt to your environment) is also quite similar to the advice provided by Lindblom (1959: 86; Cairney, 2012: 128; Quirk, 2007: 369; compare with Little, 2012: 7-8).

More importantly, its insights may become most useful when we engage fully with key issues raised by the existing policymaking literature. For example, it is difficult to avoid the charge of determinism that undermined previous socio-economic or systems approaches ('Dye-Sharansky-Hofferbert'). It is difficult to argue that complex systems should be analysed as a whole and that they exhibit 'emergence' without suggesting that they effectively have minds of their own, or at least that there is a minimal role for agents (such as policymakers) within them (Cairney, 2012: 129). While such problems (defining the relationship between structure and agency) may not have been solved by existing policy studies, there are notable attempts to explain how policymakers interpret information from their policy environments as they make decisions. This is a process still underway in complexity theory (see for example Room, 2011: 220-5; Haynes, 2008: 402).

\section{What are the Key Tenets of Public Policy Studies?}

Our discussion of complexity theory highlights the need for policy theories to go beyond inaccurate top-down and centrist majoritarian conceptions of UK policymaking, but not to go too far; to focus on the constraints within political systems while recognising the role of agency and the importance of policymakers. We should seek a sense of realism (about the limits to top-down, central government action) without resorting to fatalism (arguing that policy influence is completely out of the reach of policymakers). In this context, the production of a series of tenets, that reflect our general understanding of the policy process (as discussed above) serves three main functions. First, it allows us to go beyond a reliance on 'Westminster narrative' or 'majoritarian' style discussions to better describe policymaking during periods of crisis and 'tough' decision making - such as during the current 'age of austerity'. Second, it challenges the idea that such political circumstances are unprecedented. It allows us to balance the need to produce new terms to reflect new circumstances (as in the shift from understandings based on the ideal of comprehensive rationality) and the recognition of a 
degree of continuity in policymaking and public policy theory (as in the development of concepts such as governance). Third, it minimises the need for new theories to reinvent the wheel or, at least, it provides a context in which we can situate new discussions.

This is by no means a straightforward task. While we might agree that, in principle, it is valuable to combine the insights from many theories and concepts, we may not agree on: what those insights are; which theories should receive the most attention (and which should be avoided); and, how to combine those insights, particularly when different theories use different terms (or the same terms to mean different things) or theories appear to present competing or contradictory messages (Cairney, 2012: 266). Therefore, the following list represents the starting point for debate rather than an unbiased account of the accumulated knowledge to date. Indeed, this list of insights is biased towards challenging the idea of pervasive top-down or centralised policymaking.

Bounded Rationality and Punctuated Equilibrium Theory. Policymakers can only pay attention to a small number of the issues for which they are responsible. So, they ignore most and promote a few to the top of their agenda. For every issue to which ministers (and senior civil servants) pay attention, they must ignore (say) 99 others. The tendency to focus on that one issue, associated with major policy instability and change, draws our attention away from the 99 issues in which we might expect relative stability and continuity (Baumgartner and Jones, 2009).

Bounded Rationality and Incrementalism. The cognitive ability of policymakers, and their ability to gather information, is limited and so they tend to rely on trial-and-error strategies when developing policy. Policymakers rarely pursue radical policy change. Rather, they attempt to build on past policies because considerable effort has been invested in seeking an agreed position among a wide range of interests (Lindblom, 1959; 1979). Top-down policymaking is often 'politically expensive' and a drain on the resources of time-constrained policymakers. Consequently, it does not (or cannot) represent the 'normal' policymaking style in most political systems (Richardson et al, 1982: 10).

Policy Succession. The size of the state is such that any 'new' policy is likely to be a revision of an old one following a degree of policy failure. Policy often represents 'its own cause' (Wildavsky, 1980: 62) and apparently new policies are often pursued to address the problems caused by the old (Hogwood and Peters, 1983).

Inheritance Before Choice. Political parties make a difference but they also inherit massive commitments. Most policy decisions are based on legislation which already exists and most public expenditure is devoted to activities that continue by routine. New governments reject some commitments but accept and deliver most (Rose, 1990). 
(Multi-level) Governance. There is no single, central decision-maker or decisionmaking organisation (Rhodes, 1997; Kooiman, 1993). Instead, there are multiple centres of authority and strong central government is increasingly replaced by bargaining government and the type of 'mutual adjustments' associated with incrementalism (compare with Marsh, 2008).

Historical Institutionalism and Path Dependence. Events and decisions made in the past contributed to the formation of institutions that influence current practices. Institutions, and the practices they encourage, may remain stable for long periods of time. When commitment to a policy has been established and resources devoted to it, over time it produces 'increasing returns' (Pierson, 2000).

Street Level Bureaucracy. Although legislation is made at the 'top', it is influenced heavily by the street level bureaucrats who deliver it. Since they are subject to an immense range of (often unclear) requirements laid down by regulations at the top, they are powerless to implement them all successfully. Instead, they establish routines to satisfy a proportion of central government objectives while preserving a sense of professional autonomy necessary to maintain morale. So, radical policy change at the top may translate into routine decision making at the bottom (Lipsky, 1980).

The Advocacy Coalition Framework. Most policy change is minor, not radical. The most frequent policy changes follow attempts by coalitions of actors to adapt to their policy environments and engage in policy learning. Such policy learning takes place though the lens of deeply held policy beliefs, which effectively place limits on the consideration of new policies. Major changes are less frequent and follow 'shocks' to subsystems - prompted by, for example, the election of a new government or major socio-economic change, which affect the status of competing coalitions within subsystems (Weible et al, 2009).

The Role of Ideas. Ideas can undermine policy change if paradigms or monopolies of understanding inhibit new ways of thinking and exclude certain actors, or institutional rules and norms appear to constrain behaviour. Or, ideas can promote change, as viruses that infect systems or policy solutions used to solve problems. Change is most notable during policy failures, punctuations or shocks which produce major transformations in the way that policymakers think and act (Cairney, 2012: 228-32), but this is a relatively rare occurrence compared to the more routine process in which actors reinterpret rules and follow them selectively (2012: 81-4).

Multiple Streams Analysis. Radical policy change may happen only when a 'window of opportunity' opens and three independent streams come together - problems, policies and politics. In most cases policy does not change radically if a policy problem does 
not receive enough attention, an adequate idea or solution is not available and/ or policymakers are not receptive to the idea (Kingdon, 1984; 1995; Lieberman, 2002).

The Logic of Subgovernments and Consultation. Regular changes of government do not cause wholesale shifts in policy because most decisions are beyond the reach of ministers. The sheer size of government necessitates breaking policy down into more manageable issues involving a smaller number of knowledgeable participants. Most policy is conducted through small and specialist policy communities which process 'technical' issues at a level of government not particularly visible to the public or Parliament, and with minimal ministerial or senior civil service involvement. These arrangements exist because there is a logic to devolving decisions and consulting with certain affected interests. Ministers rely on their officials for information and advice. For specialist issues, those officials rely on specialist organisations. Organisations trade that information/ advice (and other resources such as the ability to implement or 'deliver' a large group membership) for access to, and influence within, government (Jordan and Maloney, 1997).

These insights do not preclude the identification of top-down forms of policymaking. Rather, they suggest that top-down policymaking is not the 'normal' policy style or 'standard operating procedure' of governments (Richardson et al, 1982: 2); that we need to look beyond the headlines related to 'spectacular' ministerial activity to identify the more humdrum day-to-day decisions being taken in less visible and less contentious arenas (Richardson, 1982: 199). This is an enduring concern, but it has become particularly important since a Thatcher era that was widely assumed to be marked by conviction politics (fostered by a majoritarian system), the rejection of consultation and the imposition of policy (see Marsh and Rhodes, 1992: 8 for a critical examination of this assumption).

Subsequent debates on the nature of consultation demonstrated that the British policy style varied over time, sector and issue. Although consultation appeared to be rejected at a ministerial level, it was often merely displaced to other parts of the government machine (Cairney, 2002). There were still close relationships between groups and government and a top-down process only accounted for a small proportion of the British style. These points were reinforced in the literature that critiqued discussions of Blair's 'Presidentialism' (Bevir and Rhodes, 2003; Rhodes, 2011) and suggested, in a direct qualification of Lijphart (1999), that the formal concentration of power in Britain tends to be used, 'with a certain informal restraint' (Adam and Kriesi, 2007, 140). Kriesi at al's (2006: 357-8) empirical study suggests that UK policy networks do not live up to their majoritarian or top-down reputation. Similarly, the lesson from comparisons between devolved 'consensus democracies' and the UK majoritarian system is that their policy styles (or at least their consultation styles) are not as different as their reputations 
suggest. Although the UK boasted some very high profile examples of divisive topdown policymaking, they coexisted with the 'normal' British style of consultation and negotiation (Cairney, 2008; 2009b; 2011).

These insights do not suggest that radical policy change (or political instability) is a peripheral part of the policy process. Rather, most contemporary theories seek to describe and explain the relationship between long periods of apparent stability and policy continuity punctuated by instability and major change. Crucially, however, this relationship may be a feature of all political systems and not specific to the UK.

\section{Conclusion}

When we study policymaking in the UK, we often find a strange combination of competing narratives: an enduring 'Westminster model' image (top-down, centralised, government knows best, majoritarian); and, a literature that rejects that image. Although the 'Westminster model' has become a modern day strawman, used widely to describe what does not happen in British politics, the image endures. Indeed, periods of crisis - such as the 'age of austerity' which has prompted major spending cuts and a 'radical' programme of reform - help reinforce that image in the eyes of the public and large parts of the media (although see Sergeant, 2010 for an example of 'institutional memory' in parts of the media). They may also prompt policy scholars to reconsider the adequacy of existing theories to account for new political circumstances. It is often tempting to conclude that current circumstances are so different from the past that it is difficult to learn lessons from history and current theories. Further, the literature is often subject to fluctuation as new trends emerge to explain new developments and old lessons are lost (or, in many cases, rediscovered using a different language).

In this context, the policy literature plays two main roles. First, it acts as a source of accumulated knowledge to be used to help describe and explain current events. Second, it acts as a point of departure for new theories and concepts developed to incorporate the degree of novelty in current events. Combined, our aim is to consider the extent the literature must change to reflect new circumstances, while being careful about adopting fashionable or 'new' terms that produce a lack of clarity regarding their link to old concepts and the extent to which we are describing new phenomena as well as new ideas.

The article's review of the literature shows that our approach to public policy often appears to change to reflect new circumstances. For example, it has changed significantly since the post-war period, reflecting changes in the nature of our object of study and changes to the way that we conceptualise that policymaking world. Modern theories and concepts such as governance and punctuated equilibrium have, to a large 
extent, replaced a focus on rationality and policy cycles. They seek to describe and explain newer developments, such as the move from the old 'clubby days' of politics towards a more open and complex system (with more participants) in which it is relatively difficult to monopolise or insulate decision making.

Yet, those theories also display considerable continuity. For example, most theories build on a widespread understanding of bounded rationality, which refers to the limited ability of policymakers to pay attention to the issues for which they are responsible. We can also identify a core, or relatively stable, understanding of the policymaking world in which policymakers inherit massive commitments, operate in multi-level policymaking systems in which they often have to negotiate rather than enforce policy choices, and make decisions that often reflect rather stable ideas about policy problems and how they should be solved. Indeed, we may be tempted to shift to the other extreme; to assume that this core understanding of the policymaking world is so stable as to be taken for granted. We may treat these tenets of the public policy discipline as paradigmatic and rarely questioned.

In this light, the aim of the article's production of a series of tenets in public policy research is to provide a sense of what we know about policymaking, to be used to interpret new circumstances before we consider the need to understand them in new ways. They remind us that we need to go beyond the headline images of policymaking in the UK, to examine in greater detail the relationships that policymakers and pressure participants share during periods of crisis. Can we scratch the surface and find a 'normal' style in most areas that contrasts with headline images of top-down, government knows best, policymaking? To answer this question we need to engage in research grounded in established policy theory and resist the tendency to assume that UK policymaking will reflect the caricature of its political tradition and its majoritarian institutional arrangements.

\section{References}

Adam S. and Kriesi H (2007) The Network Approach. In Sabatier P. (ed.) Theories of the Policy Process, 2nd edn. Cambridge, MA: Westview Press.

Baumgartner F and Jones B. (1993; 2009) Agendas and Instability in American Politics $1^{\text {st }}$ and $2^{\text {nd }}$ eds. Chicago: Chicago University Press.

Baumgartner F, Breunig C, Green-Pedersen C, Jones B, Mortensen P, Nuytemans M and Walgrave S. (2009) Punctuated Equilibrium in Comparative Perspective. American Journal of Political Science 53(3): 603-20.

BBC News (2010) 'Queen's Speech: Cameron hails 'radical' programme' $25^{\text {th }}$ May http://news.bbc.co.uk/1/hi/8702267.stm 
Bevir M and Rhodes R A W (2003) Interpreting British Governance. London: Routledge.

Blackman T (2001) 'Complexity theory and the new public management', Social Issues (2).

Blomquist W (2007) The Policy Process and Large-N Comparative Studies. In Sabatier P (ed.) Theories of the Policy Process 2. Cambridge MA: Westview.

Bovaird T (2008) Emergent Strategic Management and Planning Mechanisms in Complex Adaptive Systems. Public Management Review 10(3): 319-40.

Cairney P (2002) New Public Management and the Thatcher Health Care Legacy. British Journal of Politics and International Relations 4(3): 375-98.

Cairney P (2008) Has Devolution Changed the British Policy Style? British Politics 3(3): 350-72.

Cairney P (2009a) Implementation and the Governance Problem: A Pressure Participant Perspective. Public Policy and Administration 24(4): 355-77.

Cairney P (2009b) The 'British Policy Style' and Mental Health: Beyond the Headlines. Journal of Social Policy 38(4): 1-18.

Cairney P (2011a) The New British Policy Style: From a British to a Scottish Political Tradition? Political Studies Review 9(2): 208-20.

Cairney P (2011b) Comparing Policy Styles in the UK and Scotland: Beyond the Headlines. Paper to Seminar on Policy Styles, Graduate School of Law, Hokkaido University, September.

Cairney P (2012) Understanding Public Policy: Theories and Issues. Basingstoke: Palgrave.

Cohen M, March J and Olsen J (1972) A Garbage Can Model of Organizational Choice. Administrative Science Quarterly 17(1): 1-25.

Finer, S. (1972) Adversary Politics and Electoral Reform (London: Wigram).

Geyer, R. (2012) 'Can Complexity Move UK Policy beyond 'Evidence-Based Policy Making' and the 'Audit Culture'? Applying a 'Complexity Cascade' to Education and Health Policy', Political Studies, 60, 1, 20-43

Geyer R and Rihani S (2010) Complexity and Public Policy. London: Routledge. 
Hall P (1993) Policy Paradigms, Social Learning, and the State: The Case of Economic Policymaking in Britain. Comparative Politics 25(3): 275-296.

Hallsworth M, Parker S and Rutter J (2011) Policy Making in the Real World: Evidence and Analysis. London: Institute for Government.

Haynes, P. (2008) 'Complexity Theory and Evaluation in Public Management', Public Management Review, 10, 3,401-19

Heclo H (1978) Issue Networks and the Executive Establishment. In King A (ed.) The New American Political System. Washington D.C.: American Enterprise Institute.

Hjern B (1982) Implementation Research - the Link Gone Missing. Journal of Public Policy 2(3): 301-8.

Hjern B and Porter D (1981) Implementation Structures: A New Unit of Administrative Analysis. Organizational Studies 2:211-27.

Hogwood B and Peters B G (1983) Policy Dynamics. Place: St. Martin's Press.

Howard C (2005) Policy Cycle: A Model of Post-Machiavellian Policy Making? Australian Journal of Public Administration 3: 3-13.

Hupe P and Hill M (2007) Street-level Bureaucracy and Public Accountability. Public Administration 85(2): 279-99.

John P (1998) Analysing Public Policy. London: Continuum.

Jones B and Baumgartner F (2005) The Politics of Attention. Chicago: University of Chicago Press.

Jones B, Baumgartner F, Breunig C, Wleizen C, Soroka S, Foucault M, Francois A, Green-Pedersen C, Koski C, John P, Mortensen P, Varone F, Walgrave S (2009) A General Empirical Law of Public Budgets: A Comparative Analysis. American Journal of Political Science 53(4): 855-73.

Jordan G (1981) Iron Triangles, Woolly Corporatism and Elastic Nets: Images of the Policy Process. Journal of Public Policy 1(1): 95-123.

Jordan A G and Maloney W A (1997) Accounting for Subgovernments: Explaining the Persistence of Policy Communities. Administration and Society 29(5): 557-583. 
Jordan A G and Richardson J J (1982) The British Policy Style or the Logic of Negotiation?. In Richardson J J (ed.) Policy Styles in Western Europe. London: Allen and Unwin.

Jordan G, Halpin D. and Maloney W (2004) Defining Interests: Disambiguation and the Need for New Distinctions?. British Journal of Politics and International Relations 6:195-212.

Jordan G (1990) Policy Community Realism versus 'New' Institutionalist Ambiguity. Political Studies 38: 470-84.

Jordan G (2005) Bringing Policy Communities Back In? A Comment on Grant. British Journal of Politics and International Relations 7:317-21.

Jordan G (2011) Policy Styles Revisited: Still Communities, Still Consensual and Still Converging?. Paper to Graduate School of Law, Hokkaido University, September.

Keating, M. (2009) 'Putting European political science back together again', European Political Science Review, 1, 2, 297-316

Kernick D (2006) Wanted - new methodologies for health service research. Is complexity theory the answer?. Family Practice 23:385-390.

Kingdon J $(1984 ; 1995)$ Agendas, Alternatives and Public Policies $1^{\text {st }}$ and $2^{\text {nd }}$ eds. New York: Harper Collins.

Kjaer A (2004) Governance. Cambridge: Polity.

Kooiman, J. (1993) 'Socio-political Governance: Introduction’ in (ed.) J. Kooiman, Modern Governance (London: Sage).

Kriesi H, Adam S and Jochum M (2006) Comparative analysis of policy networks in Western Europe. Journal of European Public Policy 13(3): 341-361

Kuhn T (1962) The Structure of Scientific Revolutions. Chicago: University of Chicago Press.

Lerner D and Lasswell H (1951) The Policy Sciences. California: Stanford University Press.

Lieberman R C (2002) Ideas, Institutions and Political Order: Explaining Political Change. American Political Science Review 90(4): 691-712. 
Lijphart A (1999) Patterns of Democracy. New Haven: Yale University Press.

Lindblom C (1959) The Science of Muddling Through. Public Administration Review 19: 79-88.

Lindblom C (1979) Still Muddling, Not Yet Through. Public Administration Review 39:517-525.

Lipsky M (1980) Street-level Bureaucracy. New York: Russell Sage Foundation.

Little, A. (2012) 'Political Action, Error and Failure: The Epistemological Limits of Complexity’, Political Studies, 60, 1, 3-19

Majone G (1980) Policies as theories. Omega 8(2): 151-62.

Marsh, D. (2008) 'Understanding British Government: Analysing Competing Models', British Journal of Politics and International Relations, 10, 2, 251-69

Marsh D and Rhodes R A W (1992) Policy Communities and Issue Networks: Beyond Typology. I Marsh D and Rhodes R A W (eds) Policy Networks in British Government. Oxford: Oxford University Press.

McPherson A M and Raab C D (1988) Governing Education: a Sociology of Policy Since 1945. Edinburgh: Edinburgh University Press.

Mitchell M (2009) Complexity. Oxford: Oxford University Press.

Mitleton-Kelly E (2003) Ten Principles of Complexity and Enabling Infrastructures. In Mitleton-Kelly E (ed.) Complex Systems and Evolutionary Perspectives of Organisations. Amsterdam: Elsevier.

Parsons W (1995) Public Policy. Aldershot: Edward Elgar.

Pierson P (2000) Increasing Returns, Path Dependence, and the Study of Politics. The American Political Science Review 94(2): 251-267.

Quirk B (2007) The Four Things You Need to Know. Public Policy and Administration 22(3): $367-73$.

Radin B (2000) Beyond Machiavelli: Policy Analysis Comes of Age. Washington DC: Georgetown University Press.

Rhodes R A W (1994) The Hollowing Out of the State. Political Quarterly 65: 138-51. 
Rhodes R A W (1997) Understanding Governance. Buckingham: Open University Press.

Rhodes R A W (2011) Everyday Life in British Government. Oxford: Oxford University Press.

Richardson J and Jordan G (1979) Governing Under Pressure: The Policy Process In A Post-Parliamentary Democracy. Oxford: Robertson.

Richardson J J, Gustafsson G and Jordan G (1982) The Concept of Policy Style. In Richardson J J (ed.) Policy Styles in Western Europe. London: Allen and Unwin.

Richardson J J (1982) Convergent Policy Styles in Europe?. In Richardson J J (ed.) Policy Styles in Western Europe. London: Allen and Unwin.

Room G (2011) Complexity, Institutions and Public Policy. Cheltenham: Edward Elgar.

Rose R (1990) Inheritance Before Choice in Public policy. Journal of Theoretical Politics 2( 3): 263-91.

Sabatier P and Jenkins-Smith H (1993) Policy Change and Learning: An Advocacy Coalition Approach. Boulder: Westview Press.

Sabatier P (1986) Top-Down and Bottom-Up Approaches to Implementation Research: a Critical Analysis and Suggested Synthesis. Journal of Public Policy 6(1): 21-48.

Sabatier P (1991) Towards Better Theories of the Policy Process. PS: Political Science and Politics 24(2): 147-56.

Sabatier P (2007a) The Need for Better Theories. In Sabatier P (ed.) Theories of the Policy Process 2. Cambridge MA: Westview.

Sergeant, M. (2010) 'Queen's Speech: How radical are Cameron's plans?' BBC News $25^{\text {th }}$ May http://news.bbc.co.uk/1/hi/uk_politics/8703461.stm

Simon H $(1947 ; 1976)$ Administrative Behavior $1^{\text {st }}$ and $3^{\text {rd }}$ eds. London: MacMillan.

Teisman G and Klijn E (2008) Complexity Theory and Public Management. Public Management Review 10(3):287-97.

True J L, Jones B D and Baumgartner F R (2007) Punctuated Equilibrium Theory. In Sabatier P (ed.) Theories of the Policy Process $2^{\text {nd }}$ Edition. Cambridge MA: Westview Press. 
Weible C, Sabatier P and McQueen K (2009) Themes and Variations: Taking Stock of the Advocacy Coalition Framework. Policy Studies Journal 37(1): 121-41.

Wildavsky A (1980) The Art and Craft of Policy Analysis. London: MacMillan.

Wilks S and Wright M (1987) Conclusion: Comparing Government-Industry Relations: States, Sectors, and Networks. In Wilks S and Wright M (eds) Comparative Government-Industry Relations. Oxford: Clarendon Press.

\footnotetext{
${ }^{\mathrm{i}}$ Coalition governments are often associated with bargaining or the seeking of consensus. In the UK case, bargaining took place between two parties, producing a programme perhaps less open to negotiation with other parties and groups.

ii This point prompted some debate in the literature. Marsh and Rhodes (1992: 251) draw on the image of insulated policy communities and treat such arrangements as unusually stable and close. Jordan (2005: 318 ) notes that the term 'policy community' was originally used to refer to a much wider range of groupgovernment relationships driven by the 'logic of consultation' and 'bureaucratic accommodation'.

iii Note that 'punctuated equilibrium' is also used to explore change within studies of new institutionalism (see Cairney, 2012: 177; 273). This discussion refers solely to Baumgartner and Jones.

${ }^{\text {iv }}$ Note that more established policy theories also draw on concepts derived from the physical sciences such as evolution and punctuated equilibrium.
} 